\title{
GAMBARAN PENGETAHUAN PARA IBU MENGENAI BORAKS DAN FORMALIN DI LINGKUNGAN PENGASINAN
}

\author{
Elfira Maya Sari ${ }^{1}$, Siti Nurfajriah ${ }^{2}$ \\ 1. Program Studi DIII Analis Kesehatan STIKes Mitra Keluarga, Bekasi-Indonesia \\ 2. Program Studi DIII Analis Kesehatan STIKes Mitra Keluarga, Bekasi-Indonesia
}

*Korespondensi: Elfira Maya Sari | STIKes Mitra Keluarga | elfira.mayasari@stikesmitrakeluarga.ac.id

\begin{abstract}
Abstrak
Pendahuluan: Penelitian ini dilakukan untuk mengetahui gambaran pengetahuan ibu - ibu terhadap boraks dan formalin yang terkandung didalam makanan sebagai bahan pengawet berbahaya.

Metode: Lokasi penelitian berada di wilayah pengasinan, bekasi timur dengan sampel berjumlah 30 orang ibu. Penelitian dilakukan pada bulan April sampai dengan Mei 2016. Desain penelitian menggunakkan analitik kuantitatif intervensi, pengumpulan dan pengolahan data secara manual berupa hasil scoring pengetahuan.

Hasil: Dari 30 orang responden 62.5\% memiliki pengetahuan cukup, 21,9\% persen memiliki pengetahuan kurang dan sisanya memiliki tingkat pengetahuan yang baik mengenai bahan pengawet berbahaya.

Kesimpulan: Berdasarkan penelitian yang telah dilakukan, dapat disimpulkan bahwa secara keseluruhan sebanyak 20 $(62,5 \%)$ responden memiliki pengetahuan yang cukup tentang jajanan kebutuhan pokok yang mengandung bahan pengawet berbahaya dan masih ada pengetahuan yang kurang sebesar 21,9\%.
\end{abstract}

Kata Kunci : Bahan pengawet, Boraks, Formalin

Diterima 15 Oktober 2018; Accepted 30 Desember 2018

\section{PENDAHULUAN}

Bahan tambahan pangan (BTP) adalah bahan atau campuran bahan yang secara alami bukan merupakan bagian dari bahan baku pangan, tetapi ditambahkan ke dalam pangan untuk mempengaruhi sifat atau bentuk bahan pangan. BTP ditambahkan untuk memperbaiki karakter pangan agar kualitasnya meningkat. Pemakaian BTP merupakan salah satu langkah teknologi yang diterapkan oleh industri pangan berbagai skala. Sebagaimana langkah teknologi lain, maka risiko-risiko kesalahan dan penyalahgunaan tidak dapat dikesampingkan. BTP pada umumnya merupakan bahan kimia yang telah diteliti dan diuji lama sesuai dengan kaidah - kaidah ilmiah yang ada. Pemerintah telah mengeluarkan aturan-aturan pemakaian BTP secara optimal (Permenkes, 2012).

Keunggulan makanan sebagai kebutuhan pokok bagi setiap manusia. Namun, makanan yang beresiko terhadap kesehatan karena proses pengolahannya seringkali ditambahkan sebagai bahan tambahan pangan. Penggunaan boraks dan formalin sering kali disalahgunakan oleh pihak - pihak penjual untuk mengawetkan makanan. Resiko dari penggunaan bahan tambahan pangan tersebut dapat menyebabkan merah pada kulit, gagal ginjal, iritasi pada mata, iritasi pada saluran pernapasan, mengganggu kesuburan kandungan dan janin. Dosis yang dapat menyebabkan kematian atau biasa disebut dengan dosis letal pada orang dewasa adalah sebanyak 10 - 25 gram, sedangkan pada anak anak adalah sebanyak 5 - 6 gram (U.S. National Institutes of Health). Efek dari bahan tambahan pangan beracun tidak dapat langsung dirasakan, tetapi secara perlahan dan pasti dapat menyebabkan sakit.

Dari hasil analisis sampel jajanan Badan Pengawas Obat dan Makanan antara Februari 2001 hingga Mei 2003 didapatkan bahwa dari 1222 sampel, 129 (11\%) mengandung boraks dan dari 242 sampel, 80 (33\%) mengandung formalin. Pangan yang mengandung formalin adalah mie ayam, bakso, dan tahu. Sedangkan pangan yang menggunakan boraks adalah bakso, siomay, lontong, dan lemper (Anonim, 2011). Penelitian ini belum pernah dilaksanakan dalam mengukur gambaran umum pengetahuan masyarakat mengenai boraks dan formalin. Hal ini harus menjadi perhatian banyak pihak antara lain pemerintah, sekolah dan orang tua. Kurangnya perhatian dan pengawasan dapat mengakibatkan terjadinya penurunan dan gangguan kesehatan. Oleh karena itu, peneliti melakukan penelitian tentang gambaran umum pengetahuan boraks dan formalin terhadap masyarakat khususnya ibu - ibu di Lingkungan pengasinan, Bekasi timur.

\section{METODE}


A. Desain Penelitian: Jenis penelitian ini adalah analitik kuantitatif intervensi.

B. Lokasi dan waktu penelitian: Lokasi penelitian dilaksanakan di RW.3 Lingkungan Pengasinan, dengan waktu penelitian dilaksanakan pada bulan April - Mei 2016.

C. Populasi dan sampel: Populasi target adalah seluruh ibu - ibu di masyarakat RW.3 lingkungan pengasinan. Besarnya sampel yang digunakan sekitar 30 orang. Cara pengambilan sampel dengan menggunakan random sampling, karena secara geografis letak unit berjauhan. Kriteria inklusi sampel adalah ibu - ibu yang ada di Lingkungan Pengasinan yang bersedia menjadi responden dan mengisi kuesioner dengan lengkap (Rahmanita, 2011).

\section{HASIL}

Berdasarkan hasil scooring dari 30 orang responden di wilayah RW 3 pengasinan maka pengetahuan dikategorikan menjadi 3 kelompok menjadi baik, cukup, kurang. Dilihat pada tabel berikut.

Tabel 1. Univariat pengetahuan responden

\begin{tabular}{lcc}
\hline Jawaban & Frekuensi & Presentase \\
\hline Baik & 5 & $15,6 \%$ \\
Cukup & 20 & $62,5 \%$ \\
Kurang & 7 & $21,9 \%$ \\
\hline
\end{tabular}

\section{PEMBAHASAN}

Sebagian besar responden memiliki pengetahuan yang kurang yaitu sebesar 7 (21,9\%) reponden. Responden yang memiliki pengetahuan yang cukup sebanyak $20(62,5 \%)$ responden. Responden yang memiliki pengetahuan yang baik sebanyak $5(15,6 \%)$ responden. Dari beberapa pertanyaan pengetahuan yang telah diberikan kepada responden terdapat beberapa pertanyaan yang mempunyai hasil yang sangat rendah yaitu pertanyaan pengetahuan tentang ciri - ciri bahan makanan yang mengandung pengawet dan bahaya bahan pengawet tersebut terhadap kesehatan. Rendahnya pengetahuan responden mungkin dikarenakan rendahnya tingkat pendidikan responden, kurangnya informasi baik dari media cetak mupun media elektronik (Notoadmojo, Ilmu kesehatan masyarakat, 2003).

\section{KESIMPULAN}

Berdasarkan penelitian yang telah dilakukan, dapat disimpulkan bahwa secara keseluruhan sebanyak $20(62,5 \%)$ responden memiliki pengetahuan yang cukup tentang jajanan kebutuhan pokok yang mengandung bahan pengawet berbahaya dan masih ada pengetahuan yang kurang sebesar $21,9 \%$.

\section{UCAPAN TERIMA KASIH}

Terima kasih kami ucapkan kepada STIKes Mitra Keluarga yang telah mendukung terlaksananya penelitian ini melalui hibah penelitian yang diberikan, penyediaan sarana dan prasarana. Tidak lupa juga kami ucapkan terima kasih kepada seluruh civitas akademik yang telah membantu.

\section{REFERENSI}

Anonim. (2011, January 01). Bahan Tambah Illegal-Boraks, Formalin, Rhodamin. Retrieved Juny 18, 2016, from BPOM: www.BPOM.go.id

Asfawi, S., \& Ainurahmah, S. (2012). Analisis perilaku siswa terhadap kebiasaan jajan di sekitar sekolahan. Jurnal VISIKES.

Cahyadi, W. (2006). Analisis dan aspek kesehatan bahan tambahan pangan. Jakarta: Bumi aksara.

Malek, F. A., Moritz, K. U., \& Fanghanel, A. (2011, February 23). Study On spesific behavioral effects of formaldehyde in the rat. Retrieved from www.urbanfischer.de/journals/jeans

Notoadmojo, S. (2003). Ilmu kesehatan masyarakat. Jakarta: Rineka cipta.

Notoadmojo, S. (2010). Promosi kesehatan teori dan aplikasi. Jakarta: Rineka cipta.

Permenkes. (2012). Permenkes No. 33 Bahan Tambahan Pangan. Jakarta.

Rahmanita, I. (2011). Hubungan pengetahuan sikap serta perilaku ibu mengenai jajanan anak SD yang mengandung bahan pengawet dan pewarna di kelurahan beringin Jambi tahun 2011. Jakarta: UIN Syarif Hidayatullah. 
RI, D. (1999). Bahan Tambahan Pangan. Jakarta: Permenkes.

RI, P. (1988). No. 722/Menkes/Per/IX/88 Bahan Tambahan Makanan. Jakarta.

Saprinto, C., \& Hidayati, D. (2006). Bahan tambahan pangan. Yogyakarta: Kanisius.

sastroasmoro, sudigdo, \& ismael, o. s. (2010). Dasar - dasar metodologi penelitian klinis. Jakarta: Sagung seto.

SNI. (1995). 01 - 0222 - 1995. Bahan tambahan pangan. Jakarta: BSN.

Sopiyudin, D. (2009). Besar sampel dan cara pengambilan sampel dalam penelitian kedokteran dan kesehatan Edisi 2. Jakarta: Salemba Medika.

Syah, D., \& dkk. (2005). Manfaat dan bahaya bahan tambahan pangan. Bogor: IPB.

WHO. (2011, Juny 25). Formaldehyde in drinking water. Retrieved from Water Quality: www.who.or.id

WHO. (2011, Juny 25). International programme on chemical safety (IPCS) Formaldehyde. Retrieved from www.who.gov 